\title{
Morphometric evaluation of bone regeneration in segmental mandibular bone defects filled with bovine bone xenografts in a split-mouth rabbit model
}

Mariana Quirino Silveira Soares ${ }^{1,2^{*}}$, Jeroen Van Dessel ${ }^{1,2}$, Reinhilde Jacobs ${ }^{2,3}$, Renato Yassutaka Faria Yaedú1, Eduardo Sant'Ana', Danilo da Silva Corrêa', Maria Fernanda Conceição Madeira',

Marco Antônio Húngaro Duarte ${ }^{4}$ and Izabel Regina Fischer Rubira-Bullen ${ }^{1}$

\begin{abstract}
Background: Bovine bone grafts have been widely used in dentistry for guided tissue regeneration and can support new bone formation in direct contact with the graft. The aim of this study was to compare the morphometric and bone density changes after using two different bovine bone graft blocks in segmental osseous defects in the mandible of rabbits following different postoperative periods.

Material and methods: Critical size segmental defects were surgically created bilaterally in the jaw of 18 rabbits. The defects were filled with either deproteinized bovine bone mineral with 10\% collagen (DBBM-C; BioOss Collagen ${ }^{\oplus}$ ), lyophilized bovine medullary bone (LBMB; Orthogen $\left.{ }^{\circledR}\right)$, or left untreated according to a split-mouth design. Animals were sacrificed after 3 or 6 months of healing. The hemimandibles were scanned ex vivo using a high-resolution (19 $\mu \mathrm{m})$ microcomputed tomography. Morphometric and bone density parameters were calculated in the region of the defect using CT-Analyser (Bruker). Initial graft blocks were used as baseline.

Results: DBBM-C presented a denser microarchitecture, in comparison to LBMB at baseline. DBBM-C and LBMB grafted regions showed a similar progressive remodeling, with a significant decrease in structure complexity and maintenance of bone volume fraction during the postoperative follow-up periods. Both graft materials showed an enhanced bone replacement and more complex structure compared to untreated defects. The apparent fusion between the graft and host bone was observed only in the defects filled with LBMB.
\end{abstract}

Conclusion: $\angle B M B$ grafts showed a similar behavior as DBBM-C regarding structural remodeling. In LBMB samples, apparent integration between the host bone and the graft was present.

Keywords: Microcomputed tomography, Alveolar bone grafting, Bone morphometry, Deproteinized bovine bone mineral

\footnotetext{
*Correspondence: marianaqsilveira@usp.br

'Department of Surgery, Stomatology, Pathology and Radiology, Bauru

School of Dentistry, University of São Paulo, Bauru 17012-901, Brazil

${ }^{2}$ OMFS-IMPATH research group, Department of Imaging and Pathology,

Faculty of Medicine, KU Leuven and Oral and Maxillofacial Surgery, University

Hospitals Leuven, Leuven, Belgium

Full list of author information is available at the end of the article
} 


\section{Introduction}

Bone grafting is a surgical procedure that replaces missing bone with natural bone transplants (autografts, allografts, xenografts) or synthetic materials (alloplasts) [1, 2]. Autografts are harvested from a donor site in the same individual and transplanted to another site. Autografts induce bone formation with no host response and have been historically thought to be the "gold standard" for bone grafting $[3,4]$. However, there are concerns about donor site morbidity, limited bone volume, and the replacement rate can be unpredictable [4].

Xenografts are obtained from animal bone and are widely used for maxillofacial applications $[1,2,5,6]$. The xenograft most commonly used in bone regeneration procedures is the deproteinized bovine bone mineral (DBBM). This bone graft is submitted to heat (up to 300 ${ }^{\circ} \mathrm{C}$ ) and chemical treatments. After this process, the inorganic phase of bovine bone mainly consists of hydroxyapatite that provides the porous structure $[5,7]$. In order to form a scaffold block, DBBM particles can be cohesively bound with $10 \%$ biodegradable collagen matrix of porcine origin (DBBM-C) $[8,9]$. Several research papers have shown the efficacy of DBDM-C in different surgical situations [8-13].

The lyophilized bovine medullary bone (LBMB) graft is another bone block of bovine origin that differs from DBBM in the way of processing. LBMB is first chemically treated, freeze-dried, and afterwards sterilized with gamma radiation. Hereby preserving the original trabecular bone structure and organic composition consisting of type 1 collagen and hydroxyapatite $[14,15]$. Previous studies have shown that LBMB is biocompatible, osteoconductive, and has a low resorption rate [16, 17]. Additionally, no toxicity or immunogenic reactions have been reported [14, 16, 17]. Clinical reports have indicated its potential for alveolar bone defects rehabilitation [18] and sinus floor augmentation [17]. However, limited evidence is available regarding the efficacy and resorption rate of $\mathrm{LBMB}$ in comparison to other bone graft materials $[16,19]$.

The main purpose of bone graft materials is to fill the osseous defect and provide a three-dimensional spatial structure harboring cells and tissues that will colonize the graft during healing process $[1,20,21]$. In this way, the geometry and architecture of these scaffolds are critical factors that may affect bone regeneration [22]. Bone graft morphometric parameters, such as pore size, pore shape, interconnectivity, and bone surface volume density, can affect cell adhesion, proliferation, distribution, and graft resorption, thereby directly influencing the bone regeneration $[1,23]$. Additionally, bone microarchitecture at the grafte site may also play a role in the following functional rehabilitation [24]. Therefore, the aim of the present study was to investigate by means of the microcomputed tomography (micro-CT) the morphometric characteristics and bone mineral density of the two bovine bone blocks (DBBM-C and LBMB) who underwent different processing methods. Secondly, the bone replacement, resorption rate, and mineral density of both xenografts were compared with untreated experimental mandibular bone defects following 3- or 6months postoperative period.

\section{Methods}

\section{Animals and surgical procedure}

This study was approved by the Bauru School of Dentistry Animal Ethics Committee (03/2015). Eighteen male adult rabbits weighing $3.5-4.0 \mathrm{~kg}$ were included in this study and housed in individual cages. Food and water were ad libitum. The rabbits were randomly divided based on time of sacrifice into 3 (T1) and 6 months (T2) group (nine animals each).

The animals were weighted and anesthetized with a solution of Xylazine (Anasedan', Ceva, Paulínia, Brazil) $10 \mathrm{mg} /$ $\mathrm{kg}$ and Ketamine (Dopalen, Vetbrands, Vinhedo, Brazil) 50 $\mathrm{mg} / \mathrm{kg}$ intramuscularly. The surgical site was shaved and cleaned with povidone-iodine. Local anesthesia was performed with Articaine hydrochloride with adrenaline acid tartrate (Articaíne 4\% 1:100000, Nova DFL, Curicica, Brazil). A central incision following the basal cortical of the mandible was performed. Following this procedure, the tissue was dissected; the periosteum excised and detached in the buccal and lingual surfaces; and the bone exposed. Using a conic drill mounted in low-speed handpiece with extensive irrigation with saline solution, a segmental defect $(1 \times 1 \mathrm{~cm})$ which did not interrupt the mandibular continuity and involved both the lingual and buccal cortical bone was created in mandibular body, immediately anterior to the antegonial notch (Fig. 1). In 12 rabbits, a random splitmouth design was applied and defects were filled in one side with DBBM-C blocks (Bio-Oss Collagen; Geistlich, Wolhusen, Switzerland) and in the other side with LBMB blocks (Orthogen'; Genius; Baumer, Mogi Mirim, Brazil). In six animals, the bilateral defects were left untreated. Holes were drilled at an approximate distance of $3 \mathrm{~mm}$ from the bone defect and a $0.3 \mathrm{~mm}$ stainless steel wire (Aciflex , Ethicon, Johnson \& Johnson, New Brunswick, USA) was placed to stabilize the graft to the defect. Following this procedure, the region of the defect was covered with a resorbable collagenous membrane (Osseoguard, Biomet 3i, Palm Beach Gardens, USA). The periosteum and the soft tissues were replaced and sutured with a resorbable wire (Vycril, Ethicon, Jhonson \& Jhonson, New Brunswick, USA).

Immediately after surgery, rabbits were given antibiotic (0.6 mg of Shotapen ${ }^{\circ}$ L.A., Virbac) and $1.2 \mathrm{mg}$ of Ketoprofen (Ketofen ${ }^{\bullet}$ 1\%, Merial Saúde Animal, Paulínia, Brazil) intramusculary. The Ketoprofen was administered consecutively for 3 days and the antibiotic dose 


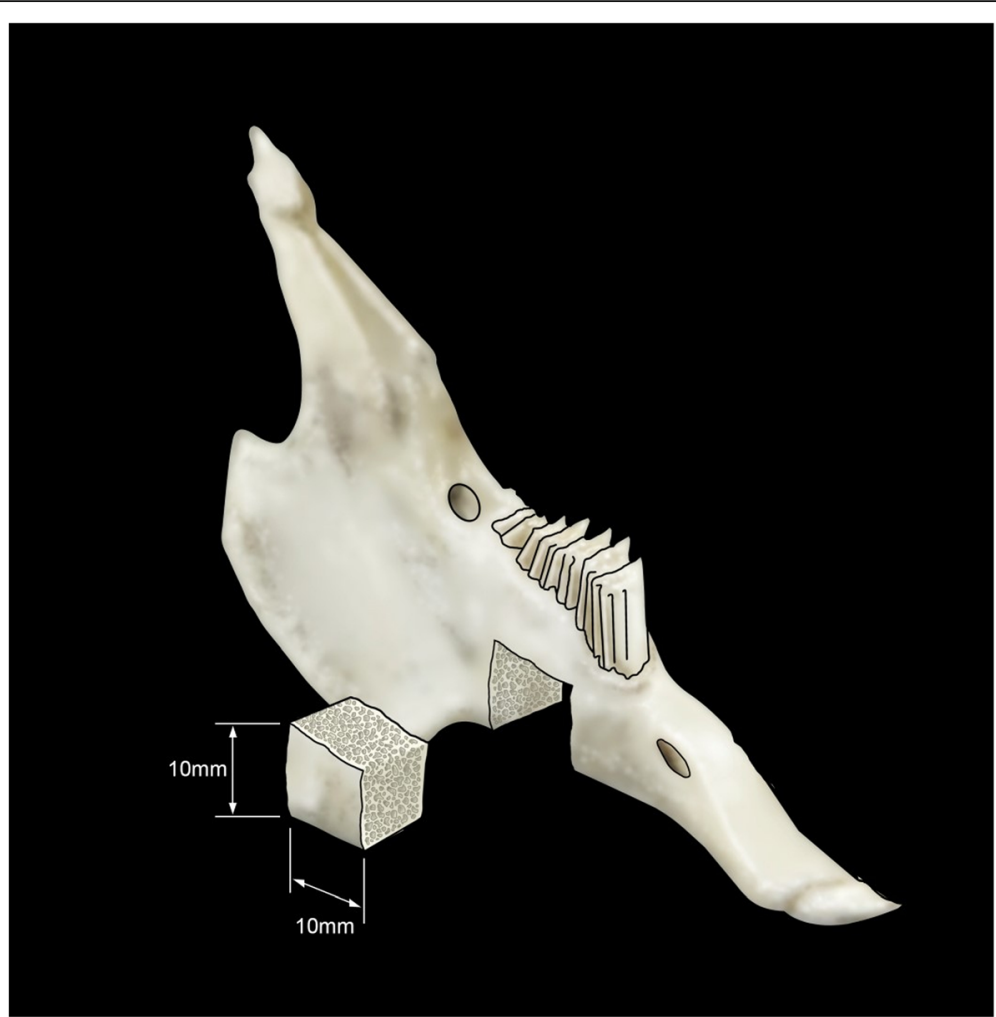

Fig. 1 Schematic drawing showing the segmental bone defect in the rabbit's jaw. The defects were made bilaterally. The segmental mandibular bone defects were made bilaterally and filed with either deproteinized bovine bone mineral with collagen (DBBM-C; Bio-oss') or lyophilized bovine medullary bone (LBMB; Orthogen ${ }^{\circ}$

was repeated after 3 days from surgery. The wounds were inspected daily for clinical signs of complications.

At sacrifice, the animals were first sedated with an intramuscular injection of Xylazine $(10 \mathrm{mg} / \mathrm{kg})$ and ketamine $(50 \mathrm{mg} / \mathrm{kg})$. Euthanasia was performed with an injection of three times higher dose of the sedation solution. The bone defects and surrounding tissue were harvested.

\section{Micro-CT}

Samples were wrapped with a damp filter paper to avoid dehydration during scanning and placed in a cylindrical sample holder. Scans were acquired using SkyScan1174 machine (Bruker, Kontich, Belgium) with the following scanning parameters: $19 \mu \mathrm{m}^{3}$ voxel size, $50 \mathrm{kVp}, 800 \mu \mathrm{A}$, frame averaging of $6,180^{\circ}$ rotations with an angular step of $0.8^{\circ}$. A $0.5 \mathrm{~mm}$ aluminum filter was used to reduce artifacts. With the same settings, a water phantom was scanned to allow bone mineral density (BMD) calibration. Four LBMB and DBBM-C blocks were scanned to characterize de initial structure of the blocks (T0). The micro-CT scans were reconstructed using the N-Recon software (Bruker, Kontich, Belgium) and the images were manually aligned using Dataviewer (Bruker, Kontich, Belgium).
A quantitative morphometric analysis was performed in CT-Analyzer (Bruker, Kontich, Belgium). A volume of interest (VOI) with the size of the defect was selected and the bone inside the VOI was segmented using an automatic adaptive threshold. Morphometric indices were calculated and grouped according to terms clinically used for bone graft evaluation [25]: (1) Bone replacement: bone volume fraction (BV/TV in \%), bone surface density (BS/TV in $\mathrm{mm}^{3} / \mathrm{mm}^{2}$ ), and trabecular thickness (Tb.Th in $\mathrm{mm}$ ); (2) Structural remodeling: trabecular number (Tb.N in $1 / \mathrm{mm}$ ), trabecular separation ( $\mathrm{Tb} . \mathrm{Sp}$ in $\mathrm{mm}$ ), connectivity density (Conn.Dn in $1 / \mathrm{mm}^{3}$ ), total porosity percentage (Po[tot] in \%), trabecular pattern factor (Tb.Pf in $1 / \mathrm{mm}$ ), structure model index (SMI); and (3) Bone density (BMD in $\mathrm{mg} \mathrm{HA} / \mathrm{cm}^{3}$ ).

\section{Statistical methods}

Descriptive analysis expressed data as mean and standard deviation. The Shapiro-Wilk test was carried out to evaluate data normality. To fully consider the effects within the split-mouth design, two separate general linear models (GLM) were estimated to examine the morphometric differences of bone graft type (DBBM-C; 
LBMB) and time (T0, T1, T2); and group (untreated, DBBM-C, LBMB) and time (T1, T2) for bone replacement, structural remodeling, and mineral density parameters. Post-hoc Bonferroni corrected $t$ tests were used to explore significant interaction effects $(\alpha=0.05)$. Statistical analysis was performed in SPSS (IBM, New York, USA).

\section{Results}

\section{General observations}

All animals recovered well from surgery and remained in good health during the rest of the experiment. The surgical procedures and follow-up showed no complications regarding the protocol. At T1 and T2, radiographic signs of inflammatory lesions were observed in one sample of LBMB and in one sample of DBBM-C.

\section{Graft block morphometry}

The original DBBM-C graft is characterized by hydroxyapatite particles connected by collagen, marked by larger bone volume $(\uparrow 42 \% \mathrm{BV} / \mathrm{TV})$ and larger surface $(\uparrow 28 \%$ BS/TV) compared to LBMB grafts (Fig. 2 and Table 1). However, no significant difference for trabecular thickness (Tb.Th) was found between both bone grafts.

In contrast, LBMB preserves the original trabecular bone structure, which explains its lower number of trabeculae ( $\downarrow 18 \%$ Tb.N), smaller number of connections $(\uparrow 114 \%$ Tb.Pf and $\downarrow 53 \%$ Conn.Dn), and larger separation between them ( $\uparrow 49 \%$ Po[tot] and $\uparrow 70 \% \mathrm{~Tb} . \mathrm{Sp})$ compared to DBBM-C (Figs. 2 and 3 and Table 1). This is in line with the structure model index parameter that indicates a concave-like structure $(\mathrm{SMI}<0)$ for DBBM-C and a plate-like structure $(\mathrm{SMI}=1)$ for LBMB. No significant difference in bone mineral density (BMD) was observed between the two grafts.

\section{Morphometric changes in the grafted defects}

There was a significant main effect of graft type for bone replacement $\left(F=4.69 ; p<0.01 ; n_{\mathrm{p}}{ }^{2}=0.37\right)$ and structural remodeling $\left(F=6.66 ; p<0.001 ; n_{\mathrm{p}}{ }^{2}=\right.$ 0.65) parameters (Fig. 3). LBMB grafted regions were characterized by significantly less bone volume $(\downarrow 51 \%$ $\mathrm{BV} / \mathrm{TV})$ and a smaller bone surface $(\downarrow 25 \% \mathrm{BS} / \mathrm{TV})$ over time compared to DBBM-C. No significant difference was observed for trabecular thickness. In general, LBMB showed smaller trabecular number $(\downarrow 34 \%$ Tb.N) and connectivity ( $\downarrow 95 \%$ Conn.Dn and $\uparrow 797 \%$ Tb.Pf), resulting in higher porosity ( $\uparrow 37 \% \mathrm{Po}[\mathrm{Tot}])$ in comparison to DBBM-C. In correspondence with the graft blocks in the baseline, the concave-like structure $(\mathrm{SMI}<0)$ and the plate-like structure $(\mathrm{SMI}=1)$ remained for DBBM-C and $\mathrm{LBMB}$, respectively. No significant difference in $\mathrm{BMD}\left(F=1.83 ; p=0.19 ; n_{\mathrm{p}}{ }^{2}\right.$ $=0.07$ ) was observed between LBMB and DBBM-C grafted regions over the postoperative periods.

There was as significant effect of postoperative followup time for bone replacement $\left(F=3.85 ; p<0.003 ; n_{\mathrm{p}}{ }^{2}=\right.$ $0.32)$, structural remodeling $\left(F=2.62 ; p=0.01 ; n_{\mathrm{p}}^{2}=\right.$ $0.42)$, and $\operatorname{BMD}\left(F=6.03 ; p=0.007 ; n_{\mathrm{p}}^{2}=0.31\right)$ parameters considering both grafts (Fig. 3 and Table 1). In comparison with baseline, after respectively 3 and 6 months, there was a significant remodeling indicated by an increased bone mineral density $(\uparrow 23 \%$ and $(\uparrow 35 \%)$, trabecular thickness ( $\uparrow 50 \%$ and $(\uparrow 67 \%)$, and separation ( $\uparrow 10 \%$ and $\uparrow 83 \%)$. This is in line with the significant decrease in trabecular number $(\downarrow 22 \%$ and $\downarrow 44 \%)$,

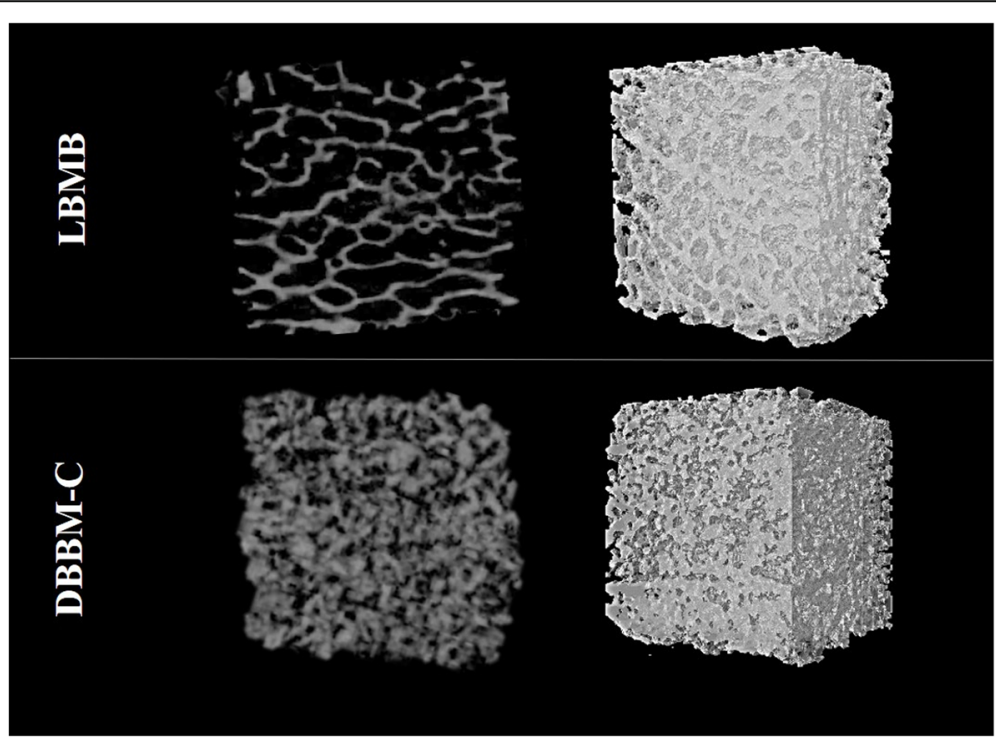

Fig. 2 Micro-CT imaging of deproteinized bovine bone mineral with Collagen (DBBM-C), lyophilized bovine medullary bone (LBMB) blocks 
Table 1 Descriptive analysis of morphometric parameters for the untreated bone defects and deproteinized bovine bone mineral with collagen (DBBM-C) and lyophilized bovine medullary bone (LBMB) for different post-operative periods

\begin{tabular}{|c|c|c|c|c|c|c|c|c|c|}
\hline \multirow{2}{*}{$\begin{array}{l}\text { Morphometric } \\
\text { parameters }\end{array}$} & \multirow[b]{2}{*}{ Unit } & \multicolumn{2}{|c|}{ Baseline line (T0) } & \multicolumn{3}{|l|}{3 months (T1) } & \multicolumn{3}{|c|}{6 months (T2) } \\
\hline & & DBBM-C & LBMB & Untreated & DBBM-C & LBMB & Untreated & DBBM-C & LBMB \\
\hline Bone mineral density & $\underset{\mathrm{cm}^{3}}{\mathrm{mg} \mathrm{HA}}$ & $\begin{array}{l}310.56 \\
(44.52)^{c}\end{array}$ & $\begin{array}{c}286.24 \\
(74.6)\end{array}$ & $\begin{array}{l}442.55 \\
(81.52)\end{array}$ & $\begin{array}{l}362.88 \\
(93.81)\end{array}$ & $\begin{array}{l}368.62 \\
(57.58)\end{array}$ & $\begin{array}{l}419.82 \\
(71.51)\end{array}$ & $\begin{array}{l}442.1 \\
(63.66)^{c}\end{array}$ & $\begin{array}{l}363.97 \\
(5.05)\end{array}$ \\
\hline Bone volume fraction & $(\%)$ & $53.86(7.57)^{\mathrm{a}}$ & $31.2(6.68)^{\mathrm{a}}$ & $22.47(7.15)^{b}$ & $\begin{array}{l}57.18 \\
(16.57)^{b, a}\end{array}$ & $\begin{array}{c}38.94 \\
(7.87)^{\mathrm{b}, \mathrm{a}}\end{array}$ & $22.54(6.52)$ & $\begin{array}{l}47.20 \\
(25.64)\end{array}$ & $\begin{array}{c}33.09 \\
(12.46)\end{array}$ \\
\hline Bone surface density & $\begin{array}{l}\left(\mathrm{mm}^{2} /\right. \\
\left.\mathrm{mm}^{3}\right)\end{array}$ & $6.55(0.66)^{a, c}$ & $\begin{array}{c}4.69 \\
(1.02)^{\mathrm{a}, \mathrm{c}}\end{array}$ & $1.72(0.50)^{b}$ & $5.20(0.85)^{b}$ & $4.25(0.80)^{b}$ & $1.64(0.29)^{b}$ & $\begin{array}{l}3.76 \\
(1.34)^{\mathrm{b}, \mathrm{c}}\end{array}$ & $\begin{array}{c}3.24 \\
(0.64)^{\mathrm{b}, \mathrm{c}}\end{array}$ \\
\hline Trabecular thickness & $(\mathrm{mm})$ & $0.27(0.02)$ & $0.22(0.03)$ & $0.47(0.06)$ & $0.37(0.10)$ & $0.37(0.12)$ & $0.58(0.15)$ & $0.44(0.15)$ & $0.38(0.09)$ \\
\hline Trabecular number & $(1 / \mathrm{mm})$ & $1.19(0.24)^{a, c}$ & $\begin{array}{c}1.41 \\
(0.26)^{\mathrm{a}, \mathrm{c}}\end{array}$ & $0.47(0.13)^{b}$ & $1.52(0.19)^{\mathrm{b}, \mathrm{a}}$ & $1.10(0.31)^{\mathrm{b}, \mathrm{a}}$ & $0.38(0.04)^{b}$ & $\begin{array}{c}1.04 \\
(0.49)^{\mathrm{b}, \mathrm{c}}\end{array}$ & $0.84(0.19)^{c}$ \\
\hline Trabecular separation & $(\mathrm{mm})$ & $0.30(0.10)^{\mathrm{a}}$ & $0.51(0.12)^{\mathrm{a}}$ & $1.55(0.47)^{b}$ & $0.35(0.11)^{\mathrm{b}, \mathrm{a}}$ & $0.54(0.15)^{b, a}$ & $1.31(0.33)^{b}$ & $0.68(0.48)^{b}$ & $0.80(0.26)$ \\
\hline $\begin{array}{l}\text { Trabecular pattern } \\
\text { factor }\end{array}$ & $(1 / \mathrm{mm})$ & $-5.76(2.56)^{a}$ & $0.81(1.14)^{\mathrm{a}}$ & $0.42(3.63)^{b}$ & $-5.61(4.86)^{b}$ & $0.4(1.73)$ & $2.61(3.05)$ & $-3.52(6.28)$ & $1(2.64)$ \\
\hline Structural model index & & $-0.38(0.75)^{a}$ & $0.95(0.27)^{a}$ & $0.57(1.95)$ & $-1.39(3.74)$ & $1.09(0.56)$ & $1.80(1.33)$ & $-0.54(2.70)$ & $1.25(0.83)$ \\
\hline Total porosity & (\%) & $46.13(7.57)^{\mathrm{a}}$ & $\begin{array}{l}68.79 \\
(6.68)^{a}\end{array}$ & $77.52(7.15)^{b}$ & $\begin{array}{c}42.81 \\
(16.57)^{\mathrm{b}, \mathrm{a}}\end{array}$ & $61.05(7.87)^{\mathrm{a}}$ & $77.45(6.52)$ & $\begin{array}{l}52.79 \\
(25.64)\end{array}$ & $66.9(12.46)$ \\
\hline Connective density & $\left(1 / \mathrm{mm}^{3}\right)$ & $20.62(4.52)^{a, c}$ & $9.65(6.58)^{a}$ & $1.63(0.88)^{b}$ & $13.04(6.14)^{b}$ & $6.94(3.08)$ & $1.24(0.60)^{b}$ & $\begin{array}{c}6.78 \\
(4.32)^{\mathrm{b}, \mathrm{c}}\end{array}$ & $3.87(1.26)$ \\
\hline
\end{tabular}

a Post-hoc showed significant statistical difference at the same time point between the grafts (LBMB and DBBM-C)

${ }^{b}$ Post-hoc showed significant statistical difference at the same time point between the untreated group and the grafts (LBMB or DBBM-C)

'Post-hoc showed significant statistical difference within the same graft experimental group (LBMB or DBBM-C) in different follow up times

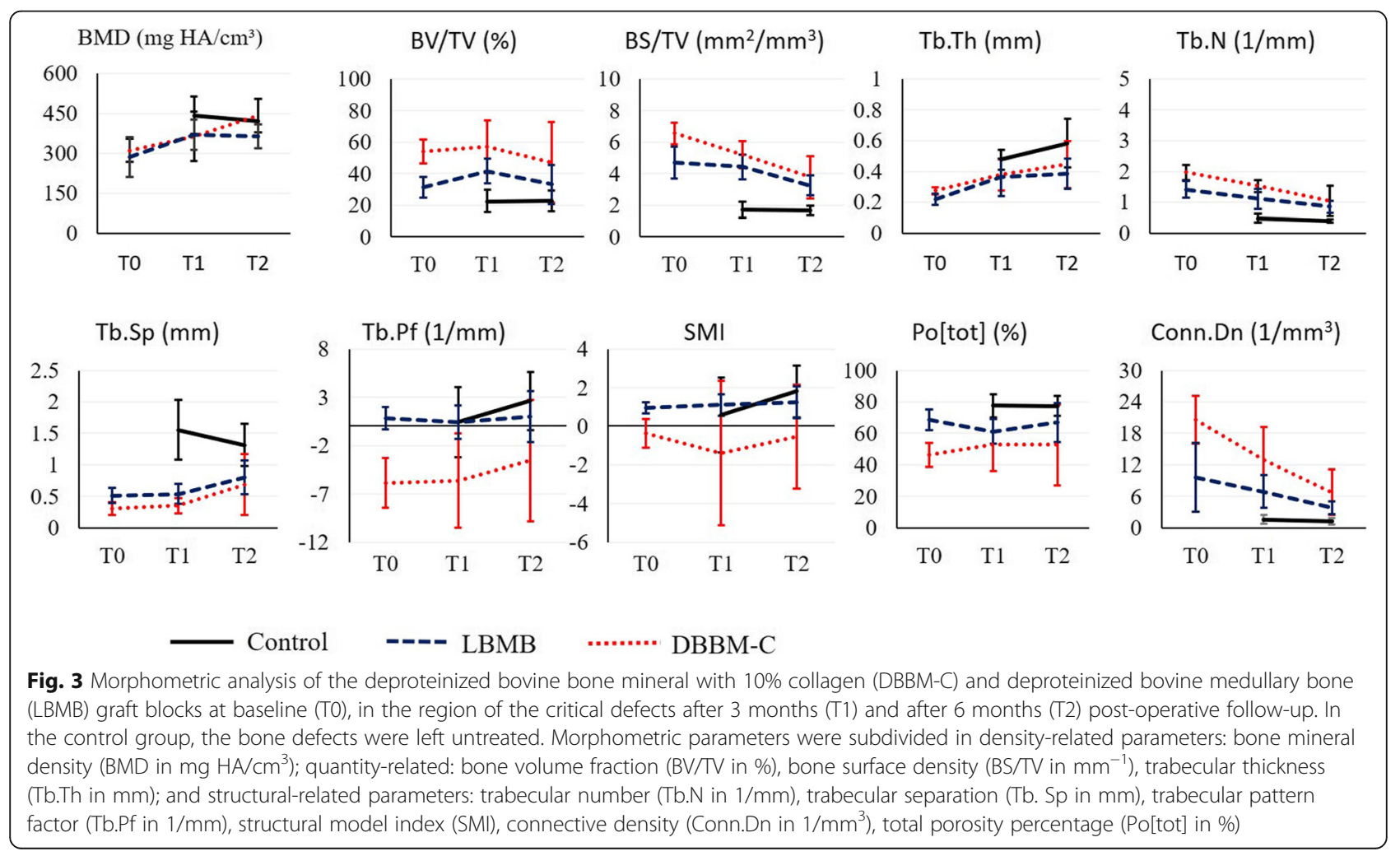


connective density ( $\downarrow 34 \%$ and $\downarrow 65 \%$ ), and bone surface density ( $\downarrow 16 \%$ and $\downarrow 38 \%)$.

The interaction between graft type and time was not significant $(p>0.05)$ for neither bone replacement, structural remodeling, and BMD parameters.

\section{Morphometric differences between bone grafts and untreated group}

There was a significant main effect of group for morphometric bone replacement $\left(F=6.46 ; p<0.001 ; n_{\mathrm{p}}{ }^{2}=\right.$ $0.38)$ and remodeling $\left(F=4.92 ; p<0.001 ; n_{\mathrm{p}}{ }^{2}=0.51\right)$ parameters (Fig. 3). In comparison to the untreated group, DBBM-C and LBMB grafted defects were respectively characterized by higher bone volume $(\uparrow 131 \%$ and $\uparrow 60 \% \mathrm{BV} / \mathrm{TV}$ ) and more complex structure, presenting higher bone surface ( $\uparrow 166 \%$ and $\uparrow 122 \% \mathrm{BS} / \mathrm{TV})$, thinner ( $\downarrow 28 \%$ and $\downarrow 21 \%$ Tb.Th), and more numerous trabeculae ( $\uparrow 194 \%$ and $\uparrow 124 \%$ ), with higher number of connections ( $\downarrow 421 \%$ and $\downarrow 50 \%$ Tb.Pf; $\uparrow 580 \%$ and $\uparrow 271 \%$ Conn.Dn). In line with these results, both DBBM-C and LBMB grafted regions also presented smaller trabecular separation ( $\downarrow 63 \%$ and $\downarrow 53 \%$ Tb.Sp) and porosity ( $\downarrow 38 \%$ and $\downarrow 17 \% \mathrm{Po}[\mathrm{Tot}])$ in relation to the controls.
In the control group, no significant effect of postoperative follow-up time was observed for bone replacement, remodeling and bone mineral density $(p>0.05)$.

\section{Interface graft-host}

All untreated defects were not completely filled with hard tissue after 6 months and showed a concave surface in the mandibular basal cortex (Fig. 4). Visually, it was possible to notice that the tissue repair process produced variable characteristics of the defect regions of each animal within the same graft group. While DBBM-C grafts adapted to the shape of the defect during repair, LBMB blocks preserved their initial square structure (Fig. 4).

In the DBBM-C group, a more corticalized bone structure was observed at the host-graft interface, while in the center of the grafted region the initial porous structure was maintained (Fig. 4). The original trabecular bone structure of LBMB grafts showed a clear integration with the adjacent host cortical bone, making it difficult to visually distinguish graft and host bone.

\section{Discussion}

The aim of this study was to compare the morphometric characteristics and bone mineral density of DBBM-C

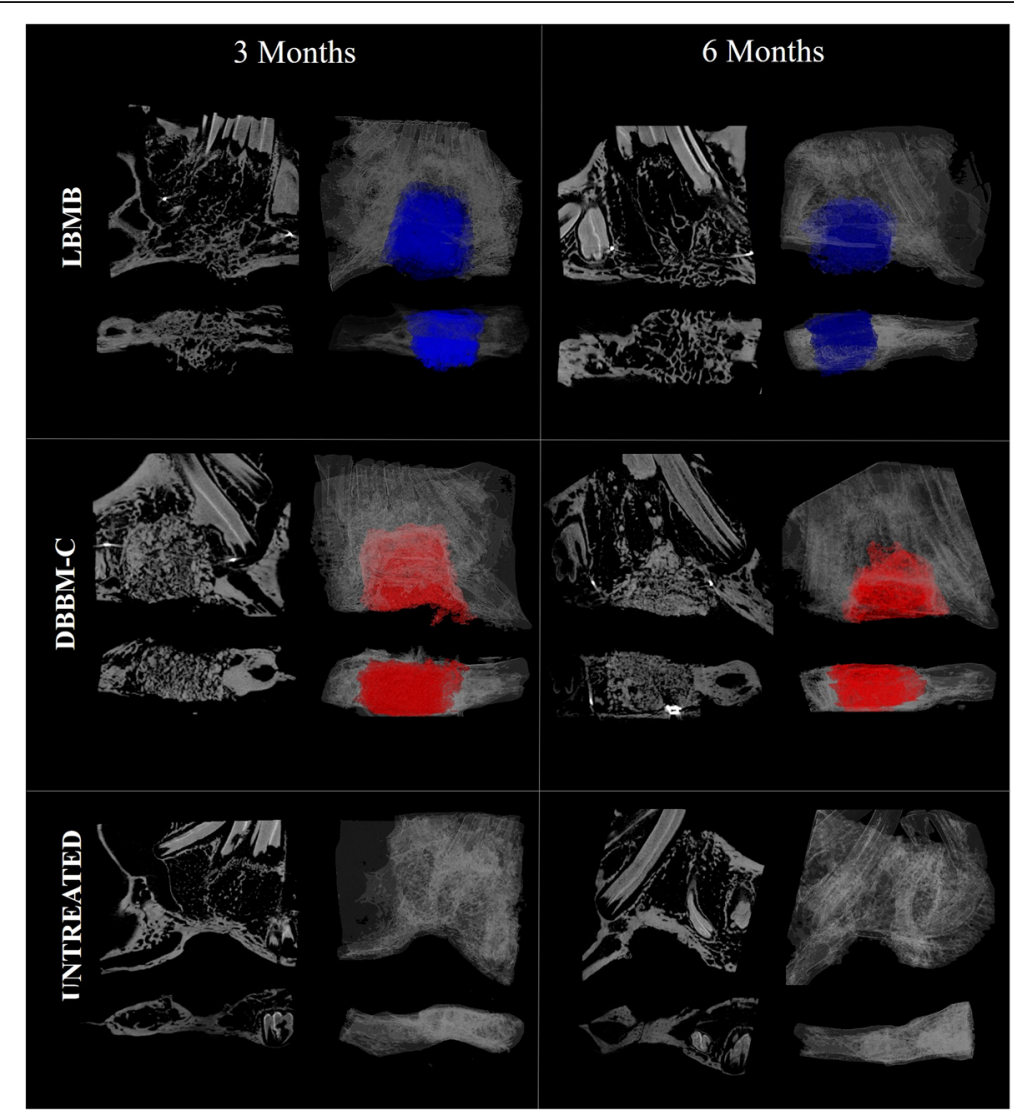

Fig. 4 Micro-CT imaging of the bony defects filled with deproteinized bovine bone mineral with collagen (DBBM-C), lyophilized bovine medullary bone (LBMB)or left untreated after 3 or 6 months post-operative follow-up 
and LBMB graft blocks. Additionally, bone replacement, remodeling, and bone mineral density of segmental defects filled with both xenografts were compared with untreated defects following 3- or 6-months postoperative period.

Original DBBM-C and LBMB blocks had a distinct morphometric structure due to the difference in processing. DBBM-C were characterized by hydroxyapatite particles bounded by collagen, while the LBMB blocks preserved the natural trabecular structure $[5,15]$. Initial DBBM-C blocks presented denser ( $\uparrow \mathrm{BV} / \mathrm{TV})$, more complex ( $\uparrow B S / T V, \uparrow T b . N)$ and connected structure ( $\downarrow$ Tb.Pf and $\uparrow$ Conn.Dn), with lower porosity ( $\downarrow \mathrm{Po}[$ Tot $]$ ) and smaller pore size ( $\downarrow$ Tb.Sp) compared to LBMB.

When comparing both blocks over time, a significant impact was induced by the grafts and the follow up time in the morphometric parameters. However, current results considering the interaction between graft and follow-up time showed no significant impact in bone replacement and remodeling morphometric parameters, suggesting similar changes for the DBBM-C and LBMB grafted regions. In relation to the untreated regions, both DBBM-C and LBMB grafts resulted in an increased bone replacement and structural complexity.

In clinical practice, guided bone regeneration with bone grafts frequently precedes implant placement in cases where insufficient bone support is available for functional rehabilitation [18, 26]. Bone microarchitecture is an important component for bone quality and may influence implant stability and rehabilitation success [24]. In accordance with our results, the microarchitecture of DBBM augmented bone has been documented as consisting of residual bone graft particles in close contact with newly formed bone leading to a dense structure [27]. These residual particles may remain unresorbed for long periods, leading to high stability in the maintaining of bone volume [27, 28]. It has been demonstrated that implant stability increases with denser bone $(\uparrow B V / T V$, $\uparrow$ Tb.Th, $\uparrow$ Tb.N, and $\downarrow$ BS/TV) plate-like structure ( $\downarrow$ SMI) and smaller marrow spaces ( $\downarrow$ Tb.Sp) [24]. Indeed, high implant success rates have been reported in DBBM grafted sites [29, 30].

In this experiment, DBBM-C blocks presented higher connective density ( $\uparrow$ Conn.Dn and $\downarrow$ Tb.Pf) compared to LBMB. This finding might have been influenced by the micro-CT segmentation. DBBM-C blocks are formed by bovine bone particles banded to each other by porcine collagen $[8,9]$. The high number of particles close to each other may lead to a miss interpretation during segmentation. In this way, connections do not reflect a real trabecular connection node. The absence of real connections explains the changes in the DBBM block shape and the significant decrease in connectivity during healing. Differently, LBMB blocks connected trabecular structure may be responsible for maintenance of connectivity and block form during bone repair.

LBMB and DBBM-C grafts presented themselves with different host-bone interfaces. In LBMB group, graft and host bone seemed to be well integrated, making it impossible to define the exact borders. In contrast, in the DBBM-C group, a hypodense line between the graft and basal cortical was often present. The formation of a bond at the graft-host interface occurs as a result of a remodeling process, and is influenced by graft osteogenic, osteoinductive properties and resorption potential, [21, 31]. The resorption rates of bovine xenografts may vary greatly among commercially available materials, influenced both by graft structure and physico-chemical properties [5, 32].

The interconnection between the graft and the host is also influenced by graft porosity. The graft structure may present sufficient porosity, pore size, and interconnectivity to allow osteoconduction [21, 33]. An open porosity above $50 \%$ and pore sizes in the range of 200 to $800 \mu \mathrm{m}$ are pointed out to be optimal for bone tissue ingrowth [21]. Scanning electron microscopy microstructural characterization of LBMB has shown 87-963 $\mu \mathrm{m}$ pore size while DBBM presented $20-200 \mu \mathrm{m}$ pore size $[15,34]$. Current results have shown that LBMB presents higher mean porosity and trabecular separation in comparison to DBBM-C and this difference is maintained in the grafted regions.

It is possible that the selection of the VOI may have influenced the morphometric quantification. This investigation was focused on the cross-sectional evaluation of the grated regions in different post-operatory moments, hence no initial imaging of the region of the defect was available for comparison and, in some cases, the exact edge of the defect was difficult to identify. To avoid mistakes, the same volume of interest considering the region of the defect was selected for all samples. The possible differences between bone architecture in the center and in the borders of the defect were not considered. Additionally, the formation of concave cortical bone in the region of the defect and within the VOI analyzed lead to an increased BMD in the untreated group in comparison to the grafted groups. Wong et al. (2010) demonstrated that the formation of new bone occurs in the DBBM-C grafted region periphery and tends to grow across the defect [10]. A similar bone neoformation pattern has also been demonstrated for LBMB [19]. In DBBM-C group, denser regions were observed in the periphery of the graft both in T1 and T2.

The results need to be interpreted in light of some limitations. Micro-CT is a non-destructive method that provides accurate 3D imaging of bone microstructure [35]. However, bone healing is a dynamic process that is influenced by several different graft material properties that should also be considered [36]. Histological investigation 
of the morphometric parameters will be the focus of further investigation. Future studies may also consider an in vivo imaging follow up of the grafted regions to allow the identification of early changes.

In this investigation, a segmental defect was constructed in the rabbit's jaw [37]. Animal models play an indispensable role to understand bone graft materials properties, such as osteoconductivity, biocompatibility, resorption, and interaction with host tissues [31]. Metabolic rate of the test animal, characteristics of the created defect, and anatomical location should be considered when evaluating the results [38]. No significant changes in bone quantity, density, and structure were observed in the non-treated defects in the interval between 3 and 6 months suggesting that segmental bone defect healing in this rabbit model have been close to completion already at 3 months.

\section{Conclusion}

Although DBBM-C and LBMB blocks had a distinct morphometric structure, LBMB grafts showed a similar bone replacement and structural remodeling as DBBM-C. Both graft materials showed an enhanced bone formation and more complex structure compared to untreated defects. Therefore, both graft are indicated for guided bone regeneration procedures in the maxillofacial region.

\section{Acknowledgements}

Not applicable.

\section{Ethics approval and consent to participant}

This study was approved by the Bauru School of Dentistry Animal Ethics Committee (research protocol 03/2015).

\section{Authors' contributions}

MQSS contributed in the study designing, data analysis, statistical analysis, and manuscript drafting. JVD contributed in the study designing, data analysis, statistical analysis, and manuscript drafting. RYFY, ES, DSC, and MFCM contributed to the study designing and were responsible for the animal experiment. MAHD contributed to the micro-CT scanning. RJ and IRFRB contributed to the study designing and manuscript drafting. All authors read and approved the final manuscript.

\section{Funding}

This research was supported by an international collaboration Latin America fund granted by KU Leuven, Leuven, Belgium. Mariana Quirino Silveira Soares receives a postdoctoral scholarship support from CAPES Foundation, Ministry of Education of Brazil (support CAPES 001). Jeroen Van Dessel is a FWO research fellow under grant $11 . \mathrm{ZU} .117 \mathrm{~N}$.

\section{Availability of data and materials}

The datasets used and/or analysed during the current study are available from the corresponding author on reasonable request.

\section{Consent for publication}

Not applicable.

\section{Competing interests}

Mariana Quirino Silveira Soares, Jeroen Van Dessel, Reinhilde Jacobs, Renato Yassutaka Faria Yaedú, Eduardo Sant'Ana, Danilo da Silva Corrêa, Maria Fernanda Conceição Madeira, Marco Antônio Húngaro Duarte, and Izabel Regina Fischer Rubira-Bullen declare that they have no competing interests.

\section{Author details}

'Department of Surgery, Stomatology, Pathology and Radiology, Bauru School of Dentistry, University of São Paulo, Bauru 17012-901, Brazil. ${ }^{2}$ OMFS-IMPATH research group, Department of Imaging and Pathology, Faculty of Medicine, KU Leuven and Oral and Maxillofacial Surgery, University Hospitals Leuven, Leuven, Belgium. ${ }^{3}$ Department of Dental Medicine, Karolinska Institutet, Stockholm, Sweden. ${ }^{4}$ Department of Dentistry, Endodontics and Dental Materials, Bauru School of Dentistry, University of São Paulo, Bauru, Brazil.

Received: 28 February 2019 Accepted: 23 August 2019

Published online: 10 September 2019

\section{References}

1. Yamada M, Egusa H. Current bone substitutes for implant dentistry. J Prosthodont Res. 2018;62:152-61. https://doi.org/10.1016/j.jpor.2017.08.010.

2. Sheikh Z, Hamdan N, Ikeda Y, Grynpas M, Ganss B, Glogauer M. Natural graft tissues and synthetic biomaterials for periodontal and alveolar bone reconstructive applications: a review. Biomaterials research. 2017;21:9. https://doi.org/10.1186/s40824-017-0095-5.

3. Sakkas A, Wilde F, Heufelder M, Winter K, Schramm A. Autogenous bone grafts in oral implantology-is it still a "gold standard"? A consecutive review of 279 patients with 456 clinical procedures. International journal of implant dentistry. 2017;3:23. https://doi.org/10.1186/s40729-017-0084-4.

4. Nkenke E, Neukam FW. Autogenous bone harvesting and grafting in advanced jaw resorption: morbidity, resorption and implant survival. European journal of oral implantology. 2014;7 Suppl 2:S203-17

5. Tadic D, Epple M. A thorough physicochemical characterisation of 14 calcium phosphate-based bone substitution materials in comparison to natural bone. Biomaterials. 2004;25:987-94

6. de Lange GL, Overman JR, Farre-Guasch E, Korstjens CM, Hartman B, Langenbach $\mathrm{GE}$, et al. A histomorphometric and micro-computed tomography study of bone regeneration in the maxillary sinus comparing biphasic calcium phosphate and deproteinized cancellous bovine bone in a human split-mouth model. Oral surgery, oral medicine, oral pathology and oral radiology. 2014;117:8-22. https://doi.org/10.1016/j.000o.2013.08.008.

7. Fienitz T, Moses O, Klemm C, Happe A, Ferrari D, Kreppel M, et al. Histological and radiological evaluation of sintered and non-sintered deproteinized bovine bone substitute materials in sinus augmentation procedures. A prospective, randomized-controlled, clinical multicenter study. Clin Oral Investig. 2017;21:787-94. https://doi.org/10.1007/s00784016-1829-9.

8. Nart J, Barallat L, Jimenez D, Mestres J, Gomez A, Carrasco MA, et al. Radiographic and histological evaluation of deproteinized bovine bone mineral vs. deproteinized bovine bone mineral with $10 \%$ collagen in ridge preservation. A randomized controlled clinical trial. Clin Oral Implants Res. 2017;28:840-8. https://doi.org/10.1111/clr.12889.

9. Alayan J, Vaquette C, Saifzadeh S, Hutmacher D, Ivanovski S. A histomorphometric assessment of collagen-stabilized anorganic bovine bone mineral in maxillary sinus augmentation - a randomized controlled trial in sheep. Clin Oral Implants Res. 2016;27:734-43. https://doi.org/1 $0.1111 / \mathrm{clr} .12652$.

10. Wong RW, Rabie AB. Effect of bio-oss collagen and collagen matrix on bone formation. The open biomedical engineering journal. 2010;4:71-6. https:// doi.org/10.2174/1874120701004010071.

11. Serrano Mendez CA, Lang NP, Caneva M, Ramirez Lemus G, Mora Solano G, Botticelli D. Comparison of allografts and xenografts used for alveolar ridge preservation. A clinical and histomorphometric RCT in humans. Clinical implant dentistry and related research. 2017;19:608-15. https://doi.org/1 $0.1111 /$ cid.12490.

12. Sculean A, Chiantella GC, Windisch P, Arweiler NB, Brecx M, Gera I. Healing of intra-bony defects following treatment with a composite bovine-derived xenograft (Bio-Oss Collagen) in combination with a collagen membrane (Bio-Gide PERIO). J Clin Periodontol. 2005;32:720-4. https://doi.org/10.1111/ j.1600-051X.2005.00758.x.

13. Alayan J, Ivanovski S. A prospective controlled trial comparing xenograft/ autogenous bone and collagen-stabilized xenograft for maxillary sinus augmentation-Complications, patient-reported outcomes and volumetric analysis. Clin Oral Implants Res. 2018;29:248-62. https://doi.org/10.1111/ clr.13107. 
14. Galia CR, Macedo CA, Rosito R, Mello TM, Camargo LM, Moreira LF. In vitro and in vivo evaluation of lyophilized bovine bone biocompatibility. Clinics (Sao Paulo). 2008:63:801-6.

15. Galia CR, Lourenco AL, Rosito R, Souza Macedo CA, Camargo LM. Physicochemical Characterization of Lyophilized Bovine Bone Grafts. Revista brasileira de ortopedia. 2011:46:444-51. https://doi.org/10.1016/S2255-4971 (15)30260-3.

16. Trotta DR, Gorny C, Jr., Zielak JC, Gonzaga CC, Giovanini AF, Deliberador TM. Bone repair of critical size defects treated with mussel powder associated or not with bovine bone graft: histologic and histomorphometric study in rat calvaria. Journal of cranio-maxillo-facial surgery : official publication of the European Association for Cranio-Maxillo-Facial Surgery. 2014;42:738-43. https://doi.org/10.1016/j.jcms.2013.11.004.

17. Lillo R, Corsini G, Venegas B, Chuhuaicura P, Beltrán V. Case Report Osteogenerative behavior of a new xenograft in a maxillary sinus lift: computed tomographic and histological findings. Int J Clin Exp Med. 2019; 12:4403-8

18. Bohner LOL, Mukai E, Mukai S, Tortamano P, Sesma N. Bone defect rehabilitation using lyophilized bone preshaped on a stereolithographic model. Contemporary clinical dentistry. 2016;7:398

19. Gehrke SA, Mazón P, Del Fabbro M, Tumedei M, Aramburú Júnior J, PérezDíaz L, et al. Histological and Histomorphometric Analyses of Two Bovine Bone Blocks Implanted in Rabbit Calvaria. Symmetry. 2019;11:641

20. Baldini N, De Sanctis M, Ferrari M. Deproteinized bovine bone in periodontal and implant surgery. Dental materials : official publication of the Academy of Dental Materials. 2011;27:61-70. https://doi.org/10.1016/j. dental.2010.10.017

21. Zizzari VL, Zara S, Tete G, Vinci R, Gherlone E, Cataldi A. Biologic and clinical aspects of integration of different bone substitutes in oral surgery: a literature review. Oral surgery, oral medicine, oral pathology and oral radiology. 2016;122:392-402. https://doi.org/10.1016/j.000o.2016.04.010.

22. Simon JL, Michna S, Lewis JA, Rekow ED, Thompson VP, Smay JE, et al. In vivo bone response to $3 \mathrm{D}$ periodic hydroxyapatite scaffolds assembled by direct ink writing. Journal of biomedical materials research Part A. 2007;83: 747-58. https://doi.org/10.1002/jbm.a.31329.

23. Sobral JM, Caridade SG, Sousa RA, Mano JF, Reis RL. Three-dimensiona plotted scaffolds with controlled pore size gradients: Effect of scaffold geometry on mechanical performance and cell seeding efficiency. Acta biomaterialia. 2011;7:1009-18. https://doi.org/10.1016/j.actbio.2010.11.003.

24. Kang SR, Bok SC, Choi SC, Lee SS, Heo MS, Huh KH, et al. The relationship between dental implant stability and trabecular bone structure using conebeam computed tomography. Journal of periodontal \& implant science. 2016;46:116-27. https://doi.org/10.5051/jpis.2016.46.2.116

25. Van Dessel J, Nicolielo LF, Huang Y, Coudyzer W, Salmon B, Lambrichts I, et al. Accuracy and reliability of different cone beam computed tomography $(C B C T)$ devices for structural analysis of alveolar bone in comparison with multislice CT and micro-CT. European journal of oral implantology. 2017;10: 95-105

26. Chavda S, Levin L. Human Studies of Vertical and Horizontal Alveolar Ridge Augmentation Comparing Different Types of Bone Graft Materials: A Systematic Review. The Journal of oral implantology. 2018;44:74-84. https:// doi.org/10.1563/aaid-joi-D-17-00053.

27. Marton K, Tamas SB, Orsolya N, Bela C, Ferenc D, Peter N, et al. Microarchitecture of the Augmented Bone Following Sinus Elevation with an Albumin Impregnated Demineralized Freeze-Dried Bone Allograft (BoneAlbumin) versus Anorganic Bovine Bone Mineral: A Randomized Prospective Clinical, Histomorphometric, and Micro-Computed Tomography Study. Materials (Basel). 2018;11. https://doi.org/10.3390/ma11020202.

28. Lindhe J, Cecchinato D, Donati M, Tomasi C, Liljenberg B. Ridge preservation with the use of deproteinized bovine bone mineral. Clin Oral Implants Res. 2014;25:786-90. https://doi.org/10.1111/clr.12170.

29. Valentini P, Abensur D, Wenz B, Peetz M, Schenk R. Sinus grafting with porous bone mineral (Bio-Oss) for implant placement: a 5-year study on 15 patients. The International journal of periodontics \& restorative dentistry. 2000;20:245-53.

30. Del Fabbro M, Testori T, Francetti L, Weinstein R. Systematic review of survival rates for implants placed in the grafted maxillary sinus. The International journal of periodontics \& restorative dentistry. 2004;24:565-77.

31. Li Y, Chen SK, Li L, Qin L, Wang XL, Lai YX. Bone defect animal models for testing efficacy of bone substitute biomaterials. Journal of orthopaedic translation. 2015;3:95-104. https://doi.org/10.1016/j.jot.2015.05.002.
32. Desterro FdPd, Sader MS, Soares GDdA, Vidigal Jr GM. Can inorganic bovine bone grafts present distinct properties? Brazilian dental journal. 2014;25: 282-8.

33. Rolvien T, Barbeck M, Wenisch S, Amling M, Krause M. Cellular Mechanisms Responsible for Success and Failure of Bone Substitute Materials. International journal of molecular sciences. 2018;19. https://doi.org/10.3390/ ijms19102893.

34. Accorsi-Mendonça T, Conz MB, Barros TC, Sena LÁd, Soares GdA, Granjeiro JM. Physicochemical characterization of two deproteinized bovine xenografts. Brazilian oral research. 2008;22:5-10.

35. Bouxsein ML, Boyd SK, Christiansen BA, Guldberg RE, Jepsen KJ, Muller R. Guidelines for assessment of bone microstructure in rodents using microcomputed tomography. Journal of bone and mineral research : the officia journal of the American Society for Bone and Mineral Research. 2010;25: 1468-86. https://doi.org/10.1002/jbmr.141.

36. Karageorgiou V, Kaplan D. Porosity of 3D biomaterial scaffolds and osteogenesis. Biomaterials. 2005;26:5474-91. https://doi.org/10.1016/j. biomaterials.2005.02.002.

37. Miloro M, Haralson DJ, Desa V. Bone healing in a rabbit mandibular defect using platelet-rich plasma. Journal of oral and maxillofacial surgery : official journal of the American Association of Oral and Maxillofacial Surgeons. 2010;68:1225-30. https://doi.org/10.1016/j.joms.2009.09.090.

38. Schlegel KA, Lang FJ, Donath K, Kulow JT, Wiltfang J. The monocortical critical size bone defect as an alternative experimental model in testing bone substitute materials. Oral Surg Oral Med Oral Pathol Oral Radiol Endod. 2006;102:7-13. https://doi.org/10.1016/j.tripleo.2005.09.011.

\section{Publisher's Note}

Springer Nature remains neutral with regard to jurisdictional claims in published maps and institutional affiliations.

\section{Submit your manuscript to a SpringerOpen ${ }^{\circ}$ journal and benefit from:}

- Convenient online submission

- Rigorous peer review

- Open access: articles freely available online

High visibility within the field

- Retaining the copyright to your article

Submit your next manuscript at $\boldsymbol{\nabla}$ springeropen.com 